\title{
Biopolítica como categoria analítica dos eventos políticos contemporâneos: nas trilhas de Esposito e Nietzsche
}

\begin{abstract}
Resumo
A discussão aqui proposta parte da leitura da biopolítica como marcador conceitual capaz de pensar de forma mais adequada as expressões da política contemporânea. A partir dessa localização, passamos à exposição do Paradigma Imunitário pensado por Roberto Esposito como dispositivo conceitual central da biopolítica. Ao fazer uso de uma metodologia analítica pretendemos colocar os conteúdos da noção de communitas e immunitas, para compreender os motivos que levam Roberto Esposito a afirmar que essa relação responde pelo próprio ciclo da biopolítica e justifica sua tomada protetiva ou letal da vida e os mecanismos de hierarquização de formas de vida. Após analisar os sentidos de comunidade, imunidade e biopolítica, passamos a investigar o que leva Esposito a entender que Nietzsche teria sido o autor que melhor compreendeu a lógica imunitária da modernidade. $O$ presente trabalho tem a intenção de mostrar que o pensamento de Esposito e sua interpretação de Nietzsche, colocam várias das questões hoje em pauta. As tomadas da vida pelo poder, os critérios de seleção e exclusão de certas formas de vida e a disputa sobre a legislação do que vem a ser o humano cuja vida vale viver. Todas essas questões são aqui retomadas como presentes em Esposito e existentes de modo subjacente em Nietzsche.
\end{abstract}

\section{Angela Couto Machado Fonseca}

Doutora em Direito pela Universidade Federal do Paraná (UFPR). Professora da Universidade Federal do Paraná (UFPR). Curitiba - PR - BRASIL fonseca_angela@yahoo.com.br orcid.org/0000-0002-0528-727X

\section{Ildenilson Meireles}

Doutor em filosofia pela Universidade Federal de São Carlos (UFSCar). Professor Universidade

Estadual de Montes Claros (UNIMONTES). Montes Claros - MG - BRASIL meirelesildenilson@gmail.com orcid.org/0000-0001-6216-8114

Palavras-chave: Paradigma Imunitário. Biopolítica. Vida.

Poder.

\section{Para citar este artigo:}

FONSECA, Angela Couto Machado; MEIRELES, Ildenilson. Biopolítica como categoria analítica dos eventos políticos contemporâneos: nas trilhas de Esposito e Nietzsche. Tempo e Argumento, Florianópolis, v. 11, n. 26, p. 530 - 547, jan./abr. 2019. 


\title{
Biopolitics as an analytical category of contemporary political events: on Esposito's and Nietzsche's track
}

\begin{abstract}
The discussion proposed here starts from the reading of biopolitics as an conceptual marker capable of thinking more accurately the expression of contemporary politics. From this initial location we turn to the exhibition of the Paradigm of Immunization thought by Roberto Esposito as a central conceptual device of biopolitics. In making use of an analytical methodology this paper intends to put the contents of the notion of communitas and immunitas in order to understand the reasons that lead Roberto Esposito to affirm that this relation responds to the cycle of biopolitics itself and justifies its protective or lethal taking of life and the mechanisms of hierarchy of life forms. After analyzing the senses of community, immunity and biopolitics, we proceeded to investigate what leads Esposito to understand that Nietzsche would have been the author who best understood the immune logic of modernity. The present work intends to show that the thought of Esposito and his interpretation of Nietzsche, put several of the issues valid today. The dynamics of power over life, the criteria of selection and exclusion of certain forms of life and the dispute over what is the human whose life is worth living. All these questions are here retaken as present in Esposito and existing in an underlying way in Nietzsche.
\end{abstract}

Keywords: Paradigm of Immunization. Biopolitics. Life. Power. 


\section{Introdução}

Desde meados da década de 70, ocorre no debate da filosofia política, uma concentração de esforços em torno do conceito de biopolítica, trabalhado por Michel Foucault e retomado por diversos autores como Hardt, Negri, Agamben e Esposito, por exemplo. Na formulação inicial de Michel Foucault, a biopolítica coloca em foco uma forma de pensar relações de poder voltadas para a gestão e administração da vida, como evento aparente desde a segunda metade do século XVIII e mais fortemente instalado no século XIX. Nessa localização, o que se destaca é a localização conceitual e temporal da biopolítica.

Autores posteriores, da escola italiana, em especial Giorgio Agamben e mais recentemente Roberto Esposito, ofertaram uma clivagem histórica mais decisiva à biopolítica. Agamben entende que a relação histórica entre soberania e vida indica um sentido biopolítico interno a essa relação, mesmo antes da segunda metade do século XVIII. Para Esposito, autor que será mais detidamente trabalhado no presente texto, a biopolítica é uma categoria analítica fundamental para compreender a política contemporânea em suas ocorrências. Para o italiano, a noções políticas clássicas como liberdade, soberania e Estado, por exemplo, já não são suficientes para compreender os eventos políticos que somente podem ser adequadamente acessados quando pensados em termos de práticas biopolíticas.

Na bastante célebre introdução de Bios: biopolitica e filosofia, o autor relata cinco acontecimentos do cenário político mundial, cuja interpretação através dos instrumentos políticos tradicionais os manteria na sua dispersão e falta de conexão. Seria pela ótica da biopolítica que tais eventos encontrariam vizinhança e possibilidade de compreensão.

Os eventos reunidos por Esposito são: 1. Uma decisão do Supremo Tribunal de Justiça da França em novembro de 2000, que reconhece a Nicolas Perruche (uma criança nascida com sérios problemas genéticos) o direito de recorrer contra médicos que não diagnosticaram a rubéola na gravidez da mãe, impedindo assim o aborto e seu direito de não nascer. 2. A guerra humanitária em novembro de 2001 no Afeganistão, que bombardeava e ao mesmo tempo jogava medicamentos e alimentos. 3. A reação ao comando checheno que fez aproximadamente mil pessoas de reféns num teatro de 
Moscou em outubro de 2002, que matou terroristas e reféns como efeitos colaterais de defesa. 4. A atuação do governo chinês noticiada em fevereiro de 2003, que repassou sangue contaminado com o vírus da Aids e apenas cuidou da não contaminação para grupos ricos. 5. O relatório da ONU, de 2004, sobre o estupro coletivo realizado em Ruanda durante a realização de genocídio consumado pelos Hutus sobre os Tutsis.

Tais acontecimentos tão díspares teriam em comum a tomada da vida pelo poder. Ou seja, a percepção da vida como objeto da atuação política contemporânea revela sua tonalidade decididamente biopolítica.

Se temos, a partir da reformulação de Esposito da proposição biopolítica foucaultiana, o olhar atento às engrenagens atuantes do poder no século XIX e XX, é Nietzsche que será apontado por Esposito como o autor que percebeu com maior profundidade a inseparabilidade entre poder e vida e, assim, mesmo que não tenha formulado a noção de biopolítica, essa temática não lhe escapou.

Em pleno século XIX, Nietzsche traz questões fundamentais sobre 0 funcionamento do poder e adianta que a disputa dos séculos vindouros se daria em torno da definição da vida humana que se estabiliza e desestabiliza a partir das modulações de poder.

O presente trabalho, utilizando de metodologia analítica, busca compreender as formulações conceituais e a análise genealógica do poder, presentes em Esposito e Nietzsche, para expor os modos como apresentam as imbricações entre poder, política e vida.

Para tanto, trabalhamos com os livros Termos da Política: Comunidade, Imunidade, Biopolítica, Bíos: biopolítica e filosofia e Communitas: origine e destino della comunità, de Roberto Esposito e Assim falou Zaratustra, Crepúsculo dos ídolos e Genealogia da Moral: uma polêmica, de Friedrich Nietzsche. 


\section{Paradigma Imunitário, biopolítica e modernidade política}

Roberto Esposito é um dos autores da escola italiana que, após Negri e Agamben, tem se destacado como pensador político e buscou realizar, nas últimas duas décadas, uma genealogia das relações entre poder e vida, para esclarecer a falta de clareza quanto ao surgimento e significado do conceito de biopolítica ${ }^{1}$. Pela sua reflexão, as questões em torno da biopolítica permitem desconstruir o léxico político moderno em voga desde Hobbes, para direcionar a gramática política a um plano mais efetivo de compreensão dos eventos atuais.

Numa passagem, elaborada em Termos da Política: Comunidade, Imunidade, Biopolítica, Esposito relata a surpresa e o espanto como as sensações suscitadas por ocorrências mundiais, como o colapso do sistema soviético e os ataques de 11 de setembro de 2001. Esposito aponta que as respostas apresentadas correm o risco de trocar a causa pelo efeito e que "a impressão é que continuamos a nos mover no interior de uma semântica não mais capaz de reconstituir partes significativas da realidade contemporânea, que de qualquer modo continuamos na superfície, ou nas margens de um movimento bem mais profundo" (ESPOSITO, 2017, p. 152). Tal movimento mais profundo exige pensar a biopolítica, essa relação entre poder e vida escamoteada pelos traços postos em visibilidade pelo discurso corrente da política moderna.

Trata-se, assim, de um diagnóstico e de uma crítica. O diagnóstico reclama que há outra cena por trás da cena visível. Um outro jogo político em andamento dentro do jogo que se crê jogar. A crítica aponta para a andança insuficiente caso não se faça o esforço de acessar essa outra cena e alcançar o jogo cujos efeitos colocam em funcionamento as mais diversas articulações sobre a vida: em sua tomada benéfica ou maléfica.

Nesse sentido, a consideração biopolítica é necessária para pensar o presente, mas esse alcance requer a consideração dos termos constitutivos e formas de funcionamento da própria biopolítica. Apenas com tal genealogia, removida do cenário e linguagem política, se poderia aceder aos seus efeitos que, não pertinentes ao modelo político visível acabam por causar surpresa.

\footnotetext{
${ }^{1}$ Sobre isso, conferir Roberto Esposito (ESPOSITO, 2010) e Timothy Campbell (CAMPBELL, 2017).
} 
Essa genealogia tem como passo fundamental a leitura inovadora que faz do Paradigma Imunitário, elemento central do ciclo biopolítico de proteção e aniquilação da vida, bem como da própria lógica política moderna que, sub-repticiamente apaga o elo entre poder e vida que lhe é inerente. Nesse sentido, o pensamento da imunidade seria a condição de melhor acesso à face biopolítica da política moderna.

Como nos lembra Timothy Campbell, "a categoria de 'imunidade' goza de uma longa e bem conhecida história na recente reflexão crítica" (CAMPBELL, 2017, p. 14), presente nos pensamentos de Donna Haraway, Derrida, Agnes Heller e Luhmann, por exemplo. Mas Esposito não permaneceria no mesmo terreno das considerações já feitas por pelo menos dois motivos. Primeiro porque eleva o alcance do conceito de imunidade política à consideração de um paradigma imunitário imanente aos processos (bio)políticos modernos. E, sobre isso, é bastante enfático ao dizer que "poderia chegarse a dizer que não foi a modernidade a colocar o problema da autoconservação da vida, mas esta última a pôr em existência, por assim dizer, a 'inventar' a modernidade como um complexo de categorias em condições de resolver tal problema" (ESPOSITO, 2017, p. 154). O paradigma imunitário não seria, nesse caso, apenas uma mola da maquinaria moderna, mas sua própria racionalidade subjacente. O segundo motivo que faz do paradigma imunitário de Esposito uma inovação, está na relação que desenha com a noção de comunidade. Immunitas e Communitas formam um complexo, um mecanismo no qual um termo está indissociavelmente ligado ao outro.

A imunidade, portanto, não é simplesmente uma licença que bloqueia ou dissolve os laços da communitas, o que as colocaria não em relação de pertinência, mas de superação. Ela é delineada como um mecanismo peculiar de proteção, uma 'proteção negativa' da vida. O termo imunidade, que transita no terreno médico e da política, opera como uma metáfora dos encontros entre poder e vida, entre bios e nomos. Se, no campo médico, a imunidade faz referência a uma proteção do organismo vivo, a um impedimento em face de uma doença pela contaminação no corpo do próprio elemento constitutivo da doença, no campo político-jurídico, trata de uma isenção em face de obrigações ou responsabilidades (ESPOSITO, 2004). 
A imunidade pensada por Esposito, nesse sentido, é uma categoria cuja própria definição já implica o encontro da esfera da vida com aquela do poder e do direito. Se vários termos políticos remetem a outros, biológicos, como corpo, constituição etc. (ESPOSITO, 2004, 41), o que sugere desdobramentos, extensões ou apropriações de uma área para a outra, a noção de imunidade quebraria a distância entre política e vida, não havendo entre elas uma relação ocasional ou incidental, mas contínua e indissociável. Isso porque a immunitas não dispõe sua leitura de poder como uma força externa, que de fora sujeita a vida e o corpo, mas, diferente disso, propõe que o próprio modo de atuação da vida é conflitual e, portanto, não pode ocorrer à revelia das relações de poder. A imunidade é inteiramente colocada como as formas de proteção da vida em sua inerente relação com o poder. Com isso, analisar a categoria immunitas no terreno da biopolítica:

Trata-se do caráter intrínseco que cinge os dois elementos de que esta última se compõe. Em vez de sobrepostos - ou justapostos - numa forma exterior que submeta um ao domínio do outro, no paradigma imunitário, bios e nomos, vida e política, resultam ser os dois componentes de um único, incindível, conjunto que só adquire sentido a partir da relação entre eles. (ESPOSITO, 2010, p. 74)

Assim, a categoria da immunitas impede pensar vida ou política de modo apartado, de modo a rejeitar, para a reflexão sobre biopolítica, um fio condutor político que vê a vida como um objeto dado e exposto às incursões do poder, da mesma maneira com que nega à dimensão da vida a sua existência independente em face das relações de poder.

Por conta dessas considerações, a immunitas será entendida como 'proteção negativa da vida'. É proteção porque significa penetrar nas relações de poder que se desdobram no interior da própria ocorrência da vida para refratar aquelas que lhes seriam fatais². Mas é negativa porque essa mesma refração que impede a aniquilação da vida é também um impedimento da livre atuação e crescimento de todas suas potências. O que

\footnotetext{
${ }^{2}$ Posteriormente, Foucault irá tocar no coração desse problema ao analisar o racismo, os projetos higienistas e as bases da lógica eugenista. O sentido imunitário não se mostrará no século XX como preservação da vida em geral a qualquer custo, mas em proteger a vida que vale viver. $\mathrm{E}$ a vida que vale viver não é o fato da vida, mas formas de vidas; vidas atravessadas por atribuições de valores e moldadas politicamente para sua preservação. Por isso, a immunitas, a um só tempo, protege, mas contém. Para proteger, é preciso proteger uma forma de vida enquadrada em critérios de validade, por isso não se trata de permitir o livre curso de suas manifestações. Aí reside a noção de 'proteção negativa'.
} 
contém protege e 'castra'3. Assim, a própria vida, na sua não condição de outro em relação ao poder, se realiza como um jogo de expansão e contenção, a immunitas é categoria do próprio movimento da vida e quando ela - vida - é tomada como objeto político, isso quer dizer que a prática dessa política da vida é prática imunitária: deve preservá-la pelo expediente de sua contenção.

Nessa sua referência de proteção negativa da vida, a immunitas mostra o sentido de ser analisada em sua relação com a noção de comunidade. No centro de cada um desses conceitos está presente o termo latino munus, que pode ser traduzido por “cargo”, “ofício”, “dever”, "graça” ou “dádiva”. Uma vez que munus é o termo comum que constitui tanto a noção de comunidade quanto a de imunidade, neste cenário estaria presente, por um lado, o aspecto conhecido das formulações teóricas da política moderna ligadas à concepção de comunidade (a partir do resgate das características tidas como inerentes à vida social) e, por outro lado, implicações referentes às técnicas de imunização, que não apenas problematizam com o ideal comunitário da política moderna, mas, sobretudo, a enviam para o campo da biopolítica.

Nisso, Esposito assinala que o movimento da política moderna somente pode ser efetivamente alcançado por via dessa análise. Se a communitas envolve os termos de um acordo comum e a divisão de "graça" e deveres - elementos estes que compõem muito mais o modo de narrar a política moderna -, sua própria face somente seria revelada diante das operações de privação dos elementos que constituem a communitas. Em outros termos, a política moderna não se revela como associação comunitária, na qual os homens dividem, gratuitamente, uma dádiva. Não há gratuidade nas relações sociais (ESPOSITO, 2004).

Aqui, aparece a leitura inovadora de Esposito acerca da communitas. Os laços da communitas, ou seja, o munus que liga pela obrigação e pelo dom, em nada se relaciona com a relação de comunidade e propriedade que o autor diz estar presente em quase todas as interpretações políticas comunitárias. Tais compreensões usuais pensam a

\footnotetext{
${ }^{3}$ Nas palavras de Esposito sobre a proteção negativa da vida: "ela salva, assegura, conserva o organismo, individual ou coletivo, a que é inerente - mas não de uma maneira direta, imediata, frontal: submetendo-o, pelo contrário, a uma condição que ao mesmo tempo lhe nega, ou reduz, a força expansiva" (ESPOSITO, 2010, p. 74).
} 
comunidade como a expressão de um 'próprio' do homem. Propriedade e comunidade numa justaposição em que a comunidade seria a realização do sujeito, um grande corpo coletivo subjetivo produzido por atributos próprios dos sujeitos e para salvaguardar tais atributos. Em suas palavras:

La verità è che tutte queste concezioni sono unite dal pressuposto irreflesso che la comunità sia una 'proprietà' dei soggetti che acommuna: un atributo, una determinazione, un predicato che li qualifica come appertenenti ad un stesso insieme. (ESPOSITO, 2006, p. VIII) ${ }^{4}$

É numa direção diversa que a análise da communitas se coloca para Esposito. Não se trata de pensar a comunidade em relação com a propriedade. Obrigação e dom constituem os laços e são laços de pura exterioridade (nenhuma realização de um próprio intrínseco) e exposição. O dom, como dom de fazer e, não de receber, é abertura e exposição ${ }^{5}$. A vida comunitária, assim, funciona nessa relação de exterioridade e entrega que produzem um continuado risco diante da exposição. O risco pertencente ao munus envia a própria para o campo do vulnerável. Se comunidade apresenta como sua forma de funcionamento exposição e risco para a vida, é preciso um remédio, uma contrapartida: a immunitas, como "salvaguarda da vida humana diante dos perigos da extinção violenta que a ameaçam" (ESPOSITO, 2017, p. 154).

A operação de imunização se caracteriza pela proteção da comunidade de que decaia em desagregação - pela sua negação, pela criação de uma rede de proteção. Protege na medida em que evita os excessos do dom comunitário, mas é negativa porque nega a comunidade - revela a passagem do comum ao individual. Diante do perigo iminente de intensificação daqueles elementos danosos da comunidade, tal rede protetiva é ativada, evitando, assim, fatores de riscos produzidos pela própria comunidade.

\footnotetext{
4 "A verdade é que todas essas concepções se unem pelo pressuposto irrefletido de que a comunidade seja uma propriedade dos sujeitos que acomuna: um atributo, uma determinação, um predicato que Ihes qualifica como pertencentes a um mesmo comum", tradução livre de ESPOSITO, 2006, XVIII.

${ }^{5}$ Como diz Esposito: “il munus che la communitas condivide non è una proprietà o un'appartenenza. Non è un avere, ma, al contrario, un debito, un pegno, un dono-da-dare (...) il commune non è caraterizzato dal proprio, ma dall'improprio" (ESPOSITO, 2006, p. XIII-XIV).
} 
Comunidade e imunidade atuam em conjunto e são imanentes uma à outra, designam "um movimento mais amplo no âmbito do qual cada termo está inscrito na lógica do outro" (CAMPBELL, 2017, p. 18).

Nesse sentido, o paradigma imunitário aborda uma contradição que é interna à própria proposta da communitas: ela requer a imunização (como defesa da vida) dos excessos da vida comum e é exatamente aquilo que tem o caráter de rejeitar essa mesma vida comum sem dissolvê-la. No centro dessa relação, figura a centralidade da vida e o ciclo da biopolítica.

Biopolítica diz respeito à compreensão da manifestação da política moderna em sua contradição interna. Por um lado, está fundamentada nos laços comunitários e, por outro lado, se sustenta exatamente nos espaços de fuga, de imunização (de proteção individual, de manutenção da vida) a que obriga o comunitário. O sentido mesmo da comunidade e da vida comum não são exercícios em favor do corpo coletivo, mas são formas de buscar no corpo coletivo (e, portanto, contra ele em sua lógica) imunização da vida. É a vida, as condições de sua permanência, o motor da política, mas para que essa construção seja viável, a modernidade política deslocou para trás de sua fachada esse alvo e o submeteu àquilo que lhe é contrário: a vida comum de um todo político.

\section{O Nietzsche de Esposito: sobre a modernidade imunitária}

Ao tratar dessa contradição da política moderna e interpretá-la à luz do paradigma imunitário, Esposito resgata o pensamento de Nietzsche que interroga incansavelmente a incapacidade da história em encarar sua apreensão não histórica, de perceber na história da cultura formulações de sentido constituídas a posteriori, usando efeitos no lugar de causas. Nietzsche critica a crença da política moderna de ver no homem social, forjado por práticas cruéis de castração, um homem originariamente social. Também seria este mesmo equívoco transportado para a justificação da ordem política, que seria alcançada por técnicas de treinamento e amansamento do homem e em nada se aproxima do mito de sujeitos que efetivam seus atributos próprios e originários pela via do contrato. $\mathrm{O}$ cenário político e histórico ao qual Nietzsche se dirige é a Europa continental do século XIX. 
Esposito lê Nietzsche como o autor que, pelo constante ataque às formulações fictícias modernas que esquecem o jogo conflitual da vida como vontade de poder, teria percebido plenamente o caráter imunitário da política. Nietzsche teria sido aquele que mais agudamente percebeu o ciclo de proteção e risco à vida que atravessa a história da cultura, as práticas políticas e o exercício de poder. Ciclo este que carrega a vida para um campo de medição, seleção e hierarquização. Se a comunidade envolve exposição e a ela se aplica o pharmacon da imunidade, existem operantes critérios divisórios de tipos de vida a serem imunizados e tipos de vida que se jogam ao risco. O que a modernidade esconde de si mesma, abaixo de sua superfície pautada por discursos homogeneizantes e universalistas, é essa sua visada valorativa que incide sobre a vida e rejeita algumas formas de sua manifestação. Nisso há uma falsidade imperante na modernidade política incapaz de perceber suas correntes subterrâneas, por isso Esposito entende que Nietzsche "é o autor que, mais do que nenhum outro, registra o esgotamento das categorias políticas modernas e a consequente abertura de um novo horizonte de sentido" (ESPOSITO, 2010, p. 117).

Se a leitura dissidente de Esposito retira da comunidade sua significação usual para expor as relações nela existentes como exposição da vida de uns face aos outros, a imunidade não seria a isenção de um dever jurídico comum, mas a proteção permitida por direitos que nunca são comuns e de todos. Em outros termos, a imunidade é o terreno das instituições e direitos. Assim, instituições e direitos não são uma capa protetiva para todos, mas endereçados a salvaguardar algumas vidas, alguns tipos de vida. É nesse sentido que Nietzsche teria capturado o sentido imunitário da modernidade, pois não se cansa de denunciar a falha e a ineficácia da lógica homogeneizante que sufoca e exclui as plurais manifestações da existência. Segundo Esposito:

Quando Nietzsche reconhece na origem das coisas não a identidade, a unidade, a pureza de uma essência não contaminada, mas sim a ferida, a multiplicidade, a alteração de qualquer coisa que já não corresponde àquilo que declara ser; quando entrevê, por trás da sucessão ordenada dos acontecimentos, e das redes de significado nas quais parecem configurar-se, o tumulto dos corpos e o proliferar dos erros, a usurpação do sentido e a vertigem da violência; quando, em suma, encontra a dissociação e o contraste no próprio coração da conciliação aparente, 
coloca um vincado ponto de interrogação sobre toda a forma ordenadora que ao longo dos séculos a sociedade européia deu a si própria. (ESPOSITO, 2010, p. 119)

Nesse aspecto, Nietzsche não apenas percebe a estrutura antinômica e falaciosa que a política moderna estabeleceu sobre si mesma, como percebe os efeitos desastrosos dessa estrutura. Se, na contemporaneidade, Foucault e, mais recentemente, Butler direcionam o olhar para as vidas e os corpos excluídos, não reconhecidos e precarizados, Nietzsche, ao tratar da história da cultura e da política como formas de formação do humano e domesticação do corpo, já percebia que as vidas fora do restrito constructo do que seria o humano válido estariam em disputa:

O extraordinário relevo - mas também o risco - de sua perspectiva biopolítica (de Nietzsche) não está apenas no colocar a vida biológica, o corpo, no centro das dinâmicas políticas, mas também na lucidez absoluta com a qual prevê que a definição da vida humana - a decisão sobre que coisa é, qual é, uma verdadeira vida humana - constituirá o mais relevante objeto dos séculos vindouros. (ESPOSITO, 2017, p. 156)

Nietzsche questiona a história veiculada pela filosofia política moderna de sujeitos racionais anteriores e exteriores às formas de poder (princípio teórico jusnaturalista do contratualismo). Essa coordenada da política moderna é problemática por diferentes motivos. Primeiro, porque acolhe a ideia de homem apartado da história, com atributos que caracterizam a sua natureza. Segundo, porque essa leitura implica também pensar o homem (seu corpo e sua vida) como alheio às técnicas que sobre ele agem para ‘humanizá-lo’ (ou se preferirmos a linguagem foucaultiana, subjetivá-lo e objetivá-lo). A humanização, como disputa pelo 'verdadeiro' humano, pode ser pensada em termos de exclusão, de precarização e em termos de imunização. Em terreno propriamente nietzscheano, os processos de humanização passam por uniformização, pelo estabelecimento de uma parte do homem tipicamente humana, idêntica e replicada em todos - espírito, alma, razão -, para remover a parte corpórea, mutável. Neste ponto, Esposito é categórico em afirmar que "quando ele (Nietzsche) transfere o foco de sua análise da alma para o corpo - ou melhor, assume a alma como a forma imunitária que ao mesmo tempo protege e aprisiona o corpo, o paradigma em questão adquire a sua particular pregnância" (ESPOSITO, 2010, p. 75). 
Nessa passagem específica, em que Esposito aponta a alma como forma imunitária do corpo no pensamento de Nietzsche, expõe-se aquilo que reiteradamente o pensamento nietzscheano reclama: toda a ordenação da vida produzida por critérios chamados de racionais e conscientes não pode operar senão como efeitos da interpretação fisiopsicológica. A própria noção de 'alma' ou 'espírito', aos quais são concedidos estatutos ontológicos que servem para fundamentar toda atividade, todo pensamento e toda a existência do homem, são na literatura nietzscheana ficções que estão a serviço de uma fixação de sentido para o homem e a natureza. Possivelmente, esse aspecto foi tomado para dizer que a alma é a forma imunitária do corpo. Ela protege o corpo na exata medida em que a atividade da consciência fixa um 'eu' e um papel (um sentido) para esse 'eu': operar como sujeito do conhecimento. O corpo, 'milagre dos milagres' (NIETZSCHE, Z), como reunião fortuita de forças, sem a construção da unidade da consciência poderia render-se a forças que o levassem à sua dissolução. Mas se a 'alma' protege, ela também 'aprisiona', como diz Esposito acerca de Nietzsche. Isso porque o corpo, fonte das interpretações que são a atividade da vontade de potência, produz interpretações que se voltam sobre esse mesmo corpo e ceifam partes de sua economia pulsional pela estabilização valorativa alcançada por algumas interpretações. Mesmo a reatividade e as práticas decadentes são indícios de atuação de forças.

Mas podemos, ainda, andar para fora do estrito sentido de alma como unidade racional, autorizados pelo próprio Nietzsche que tanto rejeita essa ficção, e pensar alma como forma de expressar todo o conceito abstrato, toda a roupagem metafísica que induz à estabilização e ontologicização do homem posto como sujeito. A alma, neste caso toda a interpretação metafísica usada como critério explicativo do homem, teria a força de abafar e regular a abertura e imprevisibilidade das atuações do corpo. A alma, agora colocada nesta perspectiva lato sensu, é forma imunitária do corpo na exata medida em que desfaz seu movimento cego e incessante ao comprimi-lo nas medidas da identidade e unidade. Em outros termos, o corpo não se perde como uma folha ao vento porque está protegido na arquitetura da alma, sendo que essa proteção é também sua corrupção.

O paradigma imunitário reclama sua vertente biopolítica ao colher, na imunidade, o elemento vital. É a vida, e não suas formas abstratas, como quer o léxico politico 
moderno, o ponto constitutivo do poder. Poder e vida, como vimos, se autoimplicam. A immunitas é atividade mesma da vida em seu funcionamento como poder. Revela sua capacidade de ‘cravar em sua própria carne’ uma ferida para a sua continuidade.

Nietzsche, por sua vez, aponta a fragilidade das concepções políticas modernas e o faz revelando o que Esposito chama da falsidade e da ineficácia de suas proposições (ESPOSITO, 2004). A falsidade se deve ao encobrimento das dinâmicas de forças efetivas que embatem sob as ideias de indivíduo, direitos naturais e Estado. A ineficácia se refere à impossibilidade de a política moderna, apoiada nesses discursos falsificantes, sustentar suas contradições. Sua contradição se revela na atuação do poder sobre a vida e não sobre sujeitos.

$\mathrm{O}$ ataque de Nietzsche à filosofia política moderna quer desnudar a politização da vida operada na leitura da vontade de poder, e no devolver seu aspecto de forças que embatem para a dominação. Sua obra desdobra um ataque contínuo às ilusões geradas para encobrir esse aspecto da vida como política. Em outros termos, Nietzsche reclama que a história política "oficial” moderna, apoiada em noções como vontade geral (uma unidade da vontade e não vontades de poder em confronto), soberania e contrato, constituem uma fábula que tem como função encobrir a dinâmica do corpo e do poder. Como nos diz Esposito:

A novidade absoluta do texto nietzschiano está na transferência da relação entre Estado e corpo do plano clássico da analogia, ou da metáfora, para o da realidade efectiva: não há política a não ser a dos corpos, sobre os corpos, através dos corpos. Neste sentido bem se pode dizer que a fisiologia - que em Nietzsche nunca está separada da psicologia - seja o próprio material da política. (ESPOSITO, 2010, p. 125)

Mas, se já no aspecto da inseparabilidade entre vida e poder, conseguimos aventar uma perspectiva biopolítica no pensamento nietzscheano, poderíamos, ainda, levar adiante essa hipótese mergulhando um pouco mais em suas sutilezas. De acordo com o que já expusemos, a história da cultura é uma história de trabalho sobre o corpo, e essa colocação se reforça na Genealogia da Moral quando Nietzsche apresenta a indigesta afirmação de que os Estados de direito são, "do mais alto ponto de vista biológico" (NIETZSCHE, GM, II, 11), Estados de exceção. Nessa passagem, a atuação de poder do 
Estado é tratada como exceção, pois reside em restringir a vida na sua visada pelo poder. O modo de restringir essa dinâmica da vida se dá pelo treinamento do corpo a ser sempre o mesmo, de conduzir-se liberando os afetos tomados como justos e lícitos e reprimindo aqueles causadores de injustiça ou ilicitude ${ }^{6}$. Em outras palavras, é exceção para Nietzsche porque o poder do Estado obriga a vida a movimentar-se contra a sua própria lógica de expansão e metamorfose.

As inclinações mutáveis dos afetos e instintos no percurso de potenciamento da vontade são vistas como alvo de treinamento/educação para a um só tempo se tornarem previsíveis (não constantemente mutáveis) e adequados. Nisso, Nietzsche percebe com agudeza que a atuação política dos Estados trata da vida e dos corpos e, não, de sujeitos de uma comunidade política.

Mas há, ainda, uma sutileza importante. Nas desconcertantes transposições para o campo do humano de termos que se referem ao tratamento das plantas e dos animais das 'menageries', vemos um Nietzsche que percebe o homem como efeito de produções operadas em nível fisiológico. Apesar do desconforto, os termos botânicos e de cultivo de formas não humanas utilizados assumem um relevante operador teórico interpretativo. Eles servem para negar uma face definitiva ao homem que está em contínuo vir-a-ser (sua economia pulsional é constante movimento e jogo conflitual).

Essa condição mesma de continuada mutação inscrita como forma de exercício da vida do homem, desse 'animal não estabilizado', mostra que a política é política da vida não apenas porque queira moldar e estabilizar os afetos, mas também e, especialmente, porque a política se apropria dessa condição da vida de mutação para regê-la, para orientá-la. Aí está a fundição mais elementar da prática política com a vida, pois a política penetra na própria lógica de funcionamento da vida e encontra aí o objeto de sua atuação. Podemos dizer que Nietzsche percebe que a política moderna se alimenta da intrínseca relação entre a vida e o poder e não é capaz de funcionar fora do seu registro,

\footnotetext{
${ }^{6}$ As técnicas de punição e prêmio são em longo prazo eficazes para ensinar o corpo a atuar de acordo com critérios maquiados como justos ou injustos. Não se trata de respeito ao justo ou injusto, mas de resposta alcançada pela interiorização das vantagens e desvantagens de agir de um ou outro modo. A exceção pensada por Nietzsche aponta para a exclusão do livre curso das funções básicas da vida: explorar, ofender, expandir e mudar.
} 
simplesmente não há um registro de poder que já não seja imediatamente o da própria vida na movimentação dos corpos. Se, por um lado, os efeitos políticos do Estado são a exceção, uma vez que penetrar na dinâmica da vida é conduzi-la contra essa mesma dinâmica, por outro lado, o exercício de potenciamento que tipifica a realização da vida (não como fundamento fixo, mas como fluxo) oferta a condição de existência e funcionamento da política em seu molde moderno.

Mas esse molde biopolítico apresenta uma face inquietante. Perceber que a vida e o corpo são constantes vir-a-ser e que isso é motor e objeto de ordenação, implica perceber também que as direções que podem ser forjadas não são mensuráveis. Segundo Esposito:

\begin{abstract}
A questão colocada por Nietzsche, que põe em causa uma coisa cujo extraordinário alcance e cujos efeitos ambivalentes só hoje estamos em condições de perceber. Trata-se da ideia de que a espécie humana não nos foi dada de uma vez para sempre, mas é susceptível, para bem e para mal, de ser plasmada em formas de que ainda não temos uma noção exata mas que, seja como for, constituem para nós um tremendo risco e um desafio irrenunciável. (ESPOSITO, 2010, p. 124)
\end{abstract}

Para Nietzsche, não se trata da vida como alvo do poder, a bios nietzscheana não é tomada pelo poder, ela é a própria atividade do poder. Nietzsche não abandona o corpo para ingressar na semântica da vida, ou melhor, corpo e vida não são pensados de modo apartado. O corpo permanece como o ponto de encontro das relações de força que em sua atividade é a vida. A dimensão de controle da vida e do homem, pelo labor e arquitetura sobre o corpo, é bastante nítida em Nietzsche.

O projeto político moderno, niilista, de negação da vida, é um projeto de rejeição da vida na rejeição das variadas potências do corpo e opera pela instauração de um tipo de vida ideal alcançável mediante programação e treinamento do corpóreo. Imunização para certas formas de vida e potências do corpo. Mas é também um projeto de manutenção da vida, aquelas às quais cabe imunizar. O homem como animal de rebanho, esse homem homogeneizado e contido (corpo social), resulta não apenas de uma interpretação moral doente, mas das práticas de adestramento biológico. Quer dizer que o rebanho é, ao mesmo tempo, rejeição da dinâmica livre da vida e garantia de sua continuidade. 


\section{Conclusão}

A visada biopolítica, que amarra a intrínseca relação entre poder e vida - entre bíos e nomos -, objeto do presente texto, é colocada como uma forma de intepretação em outros patamares da história política moderna, em geral, e dos séculos XIX e XX, em particular.

Não se trata apenas de perceber um novo relevo na história política, que no século XIX, de modo mais claro, apresenta uma reformulação das práticas de poder, agora não mais pautadas exclusivamente pelo sujeito político hobbesiano, mas voltadas a uma gestão do conjunto da vida. Mais do que isso, tratar de biopolítica e de paradigma imunitário, como fazem Esposito e também Nietzsche, é uma forma de mergulhar numa genealogia das formas de atuação de poder modernas e acusar que há uma distância entre as formulações de poder e seus exercícios. Penetrar nesse registro da busca genealógica importa em perceber a ineficácia das categorias políticas tradicionais para dar conta de fazer compreender o plano dos acontecimentos. Isso porque os acontecimentos estão relacionados a um gerir a vida e definir suas próprias significações, procedimentos esses que precisam ser alcançados pelo recorte da leitura biopolítica.

Assim, biopolítica seria um marcador interpretativo importante para acessar as práticas de poder no século XIX e XX.

\section{Referências}

CAMPBELL, Timothy. Política, imunidade, vida: o pensamento de Roberto Esposito no debate contemporâneo. In: ESPOSITO, Roberto. Termos da Política: Comunidade, Imunidade, Biopolítica. Tradução: Luiz Ernani Fritoli, Angela Couto Machado Fonseca, João Paulo Arrosi, Ricardo Marcelo Fonseca Curitiba: Editora UFPR, 2017.

CAMPBELL, Timothy. Bíos: biopolítica e filosofia. Tradução M. Freitas da Costa. Lisboa: Edições 70, 2010. 
CAMPBELL, Timothy. Termos da Política: Comunidade, Imunidade, Biopolítica. Tradução: Luiz Ernani Fritoli, Angela Couto Machado Fonseca, João Paulo Arrosi, Ricardo Marcelo Fonseca. Curitiba: Editora UFPR, 2017.

CAMPBELL, Timothy . Communitas: origine e destino dela comunità. Torino: Einaudi Editori, 2006.

FOUCAULT, Michel. A história da sexualidade 1: a vontade de saber. Tradução de Maria Thereza da Costa Albuquerque e J. A. Guilhon Albuquerque. Rio de Janeiro: Edições Graal, 1988.

FOUCAULT, Michel. Em defesa da sociedade: curso no College de France (1975-1976).

Tradução Maria Ermantina Galvão. São Paulo: Martins Fontes, 1999.

NIETZSCHE, Friedrich W. Assim falou Zaratustra: um livro para todos e para ninguém. São Paulo: Companhia das Letras, 2011.

NIETZSCHE, Friedrich W. Crepúsculo dos ídolos. São Paulo: Companhia das Letras, 2006.

NIETZSCHE, Friedrich W . Genealogia da moral: uma polêmica. São Paulo: Companhia das Letras, 1998. 